\title{
A Survey of Smart Grid Systems on Electric Power Distribution Network and Its Impact on Reliability
}

\author{
1,* Akpojedje, F. O., ${ }^{2}$ Ogujor, E. A., \& ${ }^{3}$ Idode, M. O. \\ ${ }^{1}$ Department of Electrical/Electronic Engineering Technology, National Institute of Construction Technology, Uromi, Nigeria; ${ }^{2}$ Department of \\ Electrical/Electronic Engineering, University of Benin, Benin City, Nigeria; ${ }^{3}$ PhD Scholar, University of Benin, Benin City, Nigeria. \\ *Corresponding author's e-mail: francetech007@yahoo.com
}

\begin{abstract}
This paper presents an excerpt of a more comprehensive survey of smart grid systems on electric power distribution networks and its impact on reliability. The survey was carried out as part of the feasibility study in Nigeria to determine its enhance-ability on the smartness of a conventional (traditional) distribution network. A smart grid is not a single technology but multiplex technologies in which the combination of different areas of engineering, communication and energy management systems are done. Consequently, a comprehensive review of various approaches and their impact on reliability of the network is presented. Furthermore, this paper introduces the smart grid technology and its features, reliability impacts and emerging issues and challenges that arise from the smart grid system applications. The benefit of this comprehensive survey is to provide a reference point for educational advancement on the recently published articles in the areas of smart grid systems on electric power distribution network as well as to stimulate further research interest.
\end{abstract}

Keywords

Distribution Network;

Emerging Issues and Challenges;

Reliability;

Smart Grid;

Survey.

Received 20 Feb 2019; Revised 23 March 2019; Accepted 30 Apr 2019; Available online 31 May 2019.

Copyright (C) 2019 The Authors. This is an open access article under the CC BY-NC-ND license (http://creativecommons.org/licenses/by-nc-nd/4.0/)

\section{Introduction}

Frequent power interruptions in the Nigerian electric power distribution network has become a recurrent decimal and this has been tagged as one of the biggest obstacle to be tackled in the distribution network of the electric power systems (Akpojedje et al., 2018a). The reasons for the frequent power outages (interruptions) are not far fetch from unscheduled and scheduled outages. These unscheduled interruptions are commonly predominant with conventional (traditional) electric power distribution network today. The conventional electric power distribution network has been in existence for the past decades with the inability to meet the energy demand of consumers, especially as electric power demand is ever-growing with limited resources to build new generating stations and expand the transmission and distribution networks.

The conventional (traditional) electric power distribution network is full of constraints and is clumsy to the core; and the ills of the network are: poor generation, high losses, low voltage profile, overloading, poor reliability, unbalance loading of feeders, long downtime, absence of conservative measures, inadequate fault clearance, lack of distribution automation and self-healing, load shedding etc. These constraints in the power system networks, especially the Nigerian power system network has caused the utility companies to carryout regimented load shedding over the past years and the reasons include poor system generation, equipment limitations (line, circuit breaker and transformer) management load shedding (Akpojedje et al., 2018b). These energy management methods are carried-out to manage the available power supply with ever-growing energy demand and; these energy methods are done manually in Nigerian power system today which causes several setbacks to the reliability of the network (feeders).

The advent of smart grid technologies and its applications have given leverage over the ills of the conventional electric power distribution network presently. The modernisation of the conventional distribution network through enhancing and replacing the archaic (analogue) equipment with smart once (devices) and the incorporation of two-way communication systems, automatic and optimal network 
reconfiguration, demand-side management (DSM), etc. have eliminated the ills of the conventional distribution network; hence the need of smart distribution network in the twenty-first century power system structure. The term "smart grid" is used to describe the rapid infrastructure replacement of the electrical wiring system in the Unite State (Prasad, 2014). But, express definition has been given to smart grid by several authors; hence, Prasad (2014), defined "smart grid" as simply an advanced electrical distribution system that has the capability to balance electrical loads from diverse, and often intermittent, alternative energy generation sources.

Despite that various researchers have given different definition to the term "smart grid (SG)," the meaning almost remains same. The inclusion of smart metering, demand side management, digital controls, smart appliances at the customer's premises, power electronic converter switches, solid state transformers, renewable energy storages devices and effective sensors; and dynamic optimization of power system added to the conventional distribution system to make it a smart distribution system. Consequently, this paper poses to present a survey of smart grid systems on electric power distribution network and its impact on reliability.

\section{Smart Technologies and its Features}

Smart technologies are engineering techniques applied to enhance the smartness of a system especially power system in order to increase the reliability and match the available power supply with the everincreasing energy demand in order to improve energy services. One of the ways the utility companies carried-out balance supply-demand is to incorporate distributed generators (DGs) into the system and applied supply-side management (SSM), demand side management (DSM), automated reconfiguration and smart meters. The distributed generators (DGs) cannot directly replace the existing electric grid technologies since the latter are far too well established to be abandoned, while the new technologies are not sufficiently developed to meet the total energy demand (Prasad, 2014). Therefore, it is wise to gradually infuse DGs sources into the existing grids and transform the system over time (Liserre et al., 2010).

For effective management of the infused DGs into the existing grid and increase the smartness of the network, there are certain features these new technologies must imbibe and they are as follows:

1. Distributed Energy Resources and Peak-Shaving: The Combine Heat and Power (CHP) systems such as generators (gensets), gas turbines, micro-turbines (MTs), fuel cells (FCs) that are using small-scale combined heat and power equipment together with photovoltaic (PV) modules, small wind turbines (W'Ts), other small renewables (such as biogas digestors) technologies are collectively called distributed energy resources (DERs) (Liserre et al., 2010). They are expected to play a key role in the future grid (smart grid). The presence of generating systems closer to demand can increase the power quality and reliability (POR) of electricity delivered to consumers' appliances. Indeed, DERs can be used to actively enhance PQR" (Hatziargyrio et al., 2007) of the power systems. The peak shaving is a technique deploy to reduce load during maximum loading of the system.

2. Self-Healing: It is described as the ability of a network or grid to automatically eliminate or sectionalised the faulty section from the healthy section of the grid, in order to reduce the downtime in the unaffected area. The self-healing is the most important aspect of a Smart Grid as it improves the reliability, power restoration time, grid performance and most importantly customer satisfaction (Quora, 2016).

3. Sensing: The major component of self-healing and real-time monitoring system of smart networks is the wide spread of deployment of smart sensors and smart meters (Brown \& Suryanarayanan, 2009). But smart sensors are the integral part of the smart meter. Hence, sensing and measurement have been identified as one of the fundamental technology essential for driving the creation of a smart system "Smart Grid." The ability to continuously monitor the integrity and control the response of power systems in real-time can provide for increase of efficiency, protection of power system equipment and the safety of the public. These are done through smart sensor in smart meters.

4. Smart Device: Smart devices can come in many varieties such as programmable devices, thermal devices and devices that have "Smart" circuit. The programmable devices allow the user to determine the device schedule" (Brown \& Suryanarayanan, 2009). Smart appliances, which is part of smart devices can have two different types of smart functionality: two-way communication and control algorithms set by the smart meter (Brown et al., 2010). These two functionalities of smart appliance make it function smartly in operations.

5. Islanding: Islanding mode is when a section of the grid comprising of loads and distributed energy resource (DER) change from being grid-connected to operating independently without the grid supply (Brown et al., 2010). The off-grid system which in general term Islanding is expected to function in 
smart grid in order to improve reliability and supply security. So, Islanding is an important section of "smart grid" in the twenty-first (21 st) century.

6. Automated Network Reconfiguration: This is the alteration of the topological structure of distribution feeders or feeders segment by changing automatically open and closed status of sectionalizing and tie switches placed at a strategic location in various feeders or feeders' segments for the purpose of power loss reduction or load balancing in the system. Also, it is for re-routing of power to healthy feeder segment during faulty period in order to reduce the blackout area. Note that automatic network reconfiguration is an integral part of smart grid.

7. Demand Side Management (DSM): This is the method or programmes by reducing electricity or energy usage through the promotion of activities that can enhance electric energy efficiency and conservation or more efficient management of electric loads. DSM includes load management techniques in reducing or load shifting during peak load demand. DSM which can be referred to as energy management or demand management is an integral part of smart grid. Energy conservation being one of the major DSM measure, is an important element of energy policy which leads to overall reduction of consumption and energy demand per capita (Qureshi et al., 2010).

8. Fault Location, Isolation and Service Restoration (FLISR): One of the major features that enhance smart grid network is the application of fault location, isolation and service restoration technologies that will cause a reduction or shorten the downtime of the network when fault occurs. FLISR is an integral part of smart grid network; and according to the United State Department of energy, "FLISR technologies involve automated feeder switches and reclosers, line monitors, communication networks, distribution management system (DSM), outage management system (OMS), supervisory control and data acquisition (SCADA) systems, grid analytics, models, and data processing tools.

The smart grid is a transformative set of technologies and business models. Some of the comparative analysis of the Conventional Grid and Smart Grid features are presented in Table 1 while Figure 1 presented a comparative analysis of the past grid system, present grid system and the future grid system. It also shows the effect of the technologies in enhancing the smartness of the archaic nature of the traditional or conventional grid to better it operations.

Table 1. Comparative Study of Conventional Grid and Smart Grid

\begin{tabular}{|c|c|}
\hline Conventional Grid Features & Smart Grid Features \\
\hline Centralised Generation & Distributed Generation \\
\hline Slow reaction time & Prompt reaction time \\
\hline Manual restoration & Self-healing \\
\hline One way communication & Two way communication \\
\hline No energy storage System & Energy Storage System \\
\hline Electromechanical & Digital \\
\hline Failures and blackouts & Increased customer participation \\
\hline Total control by utility & Extensive real time monitoring \\
\hline Lack of real time monitoring & Deters, detects, mitigates, and restores rapidly and efficiently \\
\hline Vulnerable to terrorists and natural disasters & Deep integration of grid intelligence with asset management \\
\hline Little integration with asset management & software \\
\hline One-way energy transfer & Two-way energy transfer \\
\hline Limited control & Relatively less T\&D losses \\
\hline Significant T \& D losses & Remote Check/Test \\
\hline Manual Check/Test & Sensors Throughout \\
\hline Few Sensors & \\
\hline
\end{tabular}

\section{Literature Survey}

The survey of related research on smart grid of electric power distribution network and its impact on reliability are classified into conventional/hardware and infrastructural based approach, software/ abstractions and simulation/communication based approach and hybrid based approach. 


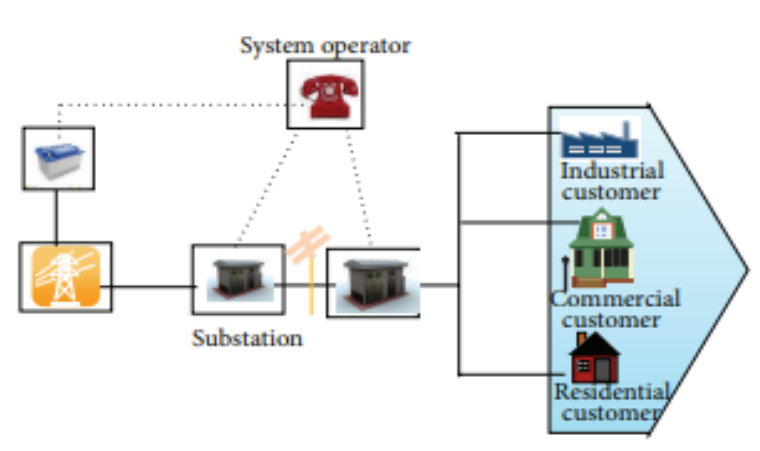

(a) Past system

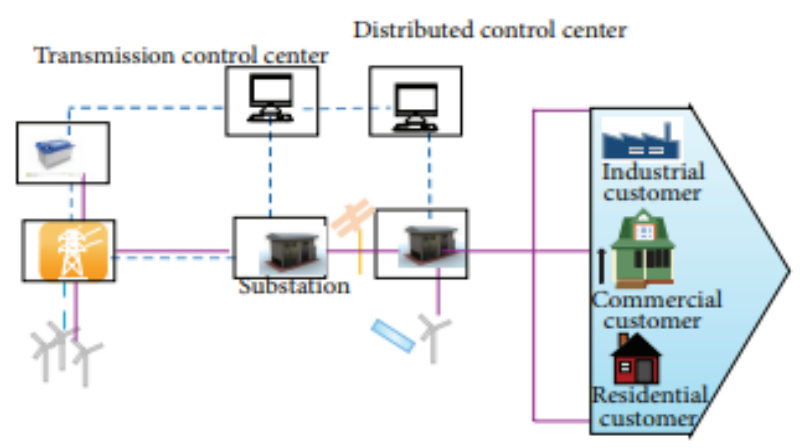

(b) Present grid system

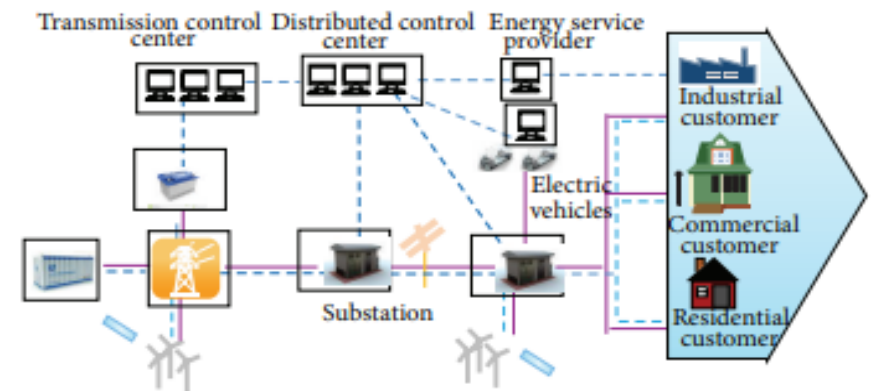

(c) Future grid system

Figure 1. A Comparative Analysis among the Past Grid System, Present Grid System and Future Grid System (TRSG, 2011).

\subsection{Conventional/Hardware and Infrastructural Based Approaches}

Many researchers have published on existing approaches applied to smart grid of electric distribution network and its impact on reliability. For instances many authors such as Zhang et al. (2012) described the current situation in China in the fields of smart grid and development strategies that Hitachi have formulated to keep pace with the nation's progress and energy management. The Hitachi technological know-how in the fields of energy efficiency and environmental protection has led to increasingly globalised and localized approached in designing Chinese's smart grid and Chinese's smart cities, specifically network simulator technology for the analysis of electric power distribution networks and technology for energy management systems.

Sagar \& Prasad (2013) presented the concept and characteristics of smart grid distribution systems, basic difference between conventional and smart grid distribution systems, functional management and reliability evaluation of smart grid distribution systems. The impact of smart grid technology on the reliability of radial distribution system was investigated and the reliability indices of a radial distribution system for: (i) conventional (non-automated); (ii) automated; and (iii) smart grid configurations were calculated and the results were compared. The results showed that the smart grid technology improves the quality and reliability of power supply and also reduces the power losses in the system.

Guo \& Qin (2014) presented a reliable intelligent distribution network construction experience. The level of distribution automation development both at home and abroad were described on the basis of combined practical engineering experience and reliable structure of smart distribution network. At end of the work, the construction of the key technology of intelligent and reliable distribution network was highlighted.

Nomura et al. (2014) outlined the solutions that are expected to be necessary in the future for utilisation of Smart Meters. The solutions that will be used by both the demand and supply sides of power and also, serve as a foundation for the Smart Grid to be introduced in future was described in details. The roles of the individual solutions were described as important because they will create multiplier effect when smart meters are fully deployed. Conclusively, offering the solutions that will keep up with the needs of the times is Fujitsu mission and a role it is expected to play in smart networks.

Cardenas et al. (2012) suggested a smart substation that have the capabilities of utilising electrical system more efficiently and smartly. This work reflects the actual development of complete substation protection, control and monitoring systems, taking the advantage of the modern IEDs with IEC61850 communication protocol. In their paper, a SoftPLC was used to manage IEC61850 including GOOSE 
capabilities as well as synchro-phasor which is capable of carrying-out PDCs and PMUs measurements in the network. A full controlled load restoration was also achieved by the SoftPLC that was integrated in the upper system level which enables the system to unify the most complex logics and to create an advanced interface with the operator where the topologies and scenarios can be modified under any circumstances as required in the substation.

Prasad (2014) presented a state of the art of a smart grid along with the vision, application, control, problems, government issues, research and academic authorities; and implementation of smart grid technologies. The issues with smart grid and it roles of making conventional grid more resilience and reliable was examined and also, the design and implementation of Supervisory Control and Data Acquisition (SCADA) for smart grid monitoring and control which is based on microcontroller for customer's side distribution automation system was done. The results showed that the system designed and implemented gave excellent result in the data collected, transmitted, monitored and the system control application.

Mohassel et al. (2014) presented a basic information regarding Advanced Metering Infrastructure (AMI) technology and its current status as the foundation of Smart Grid (SG). The issues covering the utilisation of AMI in electrical smart grids such as: smart devices, communication, data management system and also, emerging security challenges in application of AMI were elaborately dealt-with. The areas of security challenges were categories into three: end user's privacy, security against external cyber or physical attacks and power theft, which effects were extensively elaborated especially power theft methods of electromechanical meters. In addition, the attackers and their motivations were studied. At the end of the research, the survey showed that advanced metering infrastructure is a relatively new concept which needs improvement in the areas of communication, data analysis and control schemes when harnessing.

Puradbhat \& Banerjee (2014) described a framework for estimating end-use based demand side management (DSM) impacts in a commercial building. It consists of a generalised methodology adopted for DSM programme designed for estimating DSM impacts on the building's electricity load profile and assessing its economic viability. The generalised method used comprises of obtaining electricity data, segregating the data into end-uses, designing DSM strategies based on end-uses and then estimating their impacts and economic viability. A case study was implemented on main administrative building, IIT Bombay and the results showed that cost of energy saved for most of the DSM options is found to be below the average price of electricity based on the designed DSM strategies, while the conservation supply curve indicate the economic feasibility of the DSM options.

Meyer et al. (2012) developed a generic system which enables individual devices to autonomously determine their power consumption given the current circumstances and the owner's preferences. A design science approach was adopted for the development and evaluation of the system which is based on the concept of intelligent (smart) products. The intelligent products represent individual devices such as home appliances and electric vehicles and, are capable of autonomously performing some of the repetitive tasks required for determining their power consumption through the three levels of intelligence such as: information handling, problem detection and decision making to balance supply and demand. Two scenarios were described: home appliance in a home area network and electric vehicles in a parking lot which have been used to demonstrate the feasibility and usefulness of the suggest system. The results showed a balance supply and demand, without overloading the power lines and the transformers.

A smart grid can be defined as a "system that employs digital information and control technologies to facilitate the deployment and integration of distributed and renewable resources, smart consumer devices, automated systems, electricity storage and peak-saving technologies" (Joy et al., 2013). The concept of smart grid that can efficiently manage and increase reliability of the power systems is shown in Figure 2. Also, Figures $3-5$ illustrate the application of multi-agent system (MAS) and demand side management (DSM), grid modernisation and smart grid pillars respectively. Their relationship and implementation in enhancing and modernising the archaic features of conventional grid to a grid for the future called the smart grid is also depicted.

Qureshi et al. (2010) presented a load management technique as a partial solution towards addressing the current energy crisis (capacity shortfall issue) in Pakistan. An efficient load management of air conditioning load (ACL) control using the same principle as Ripple Control Techniques which was called energy savings priority circuit was suggested and tested in two scenarios as case study. The results and analysis showed that the projected energy conserved method does not only solve energy shortage but also reduce the peak demand to a significant level in Pakistan during summer. Conclusively, scaling it up for practical implementation, and the savings priority circuit proposed can be rolled out by distribution utilities in Pakistan on similar lines as the ripple control. 


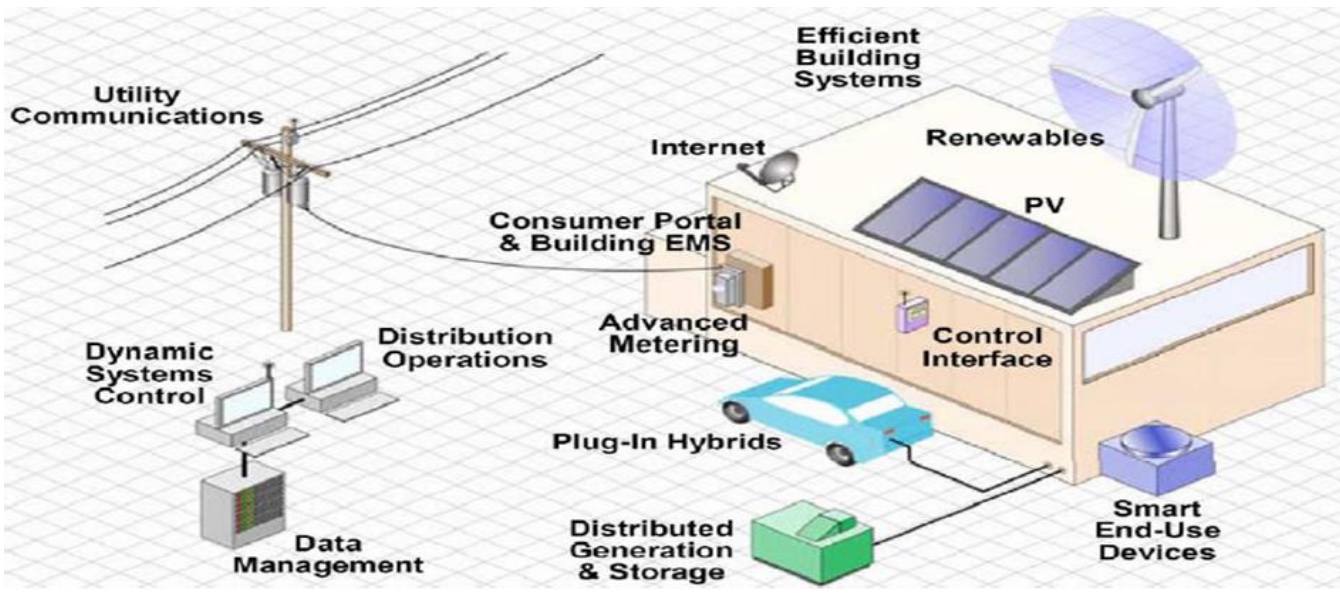

(a)

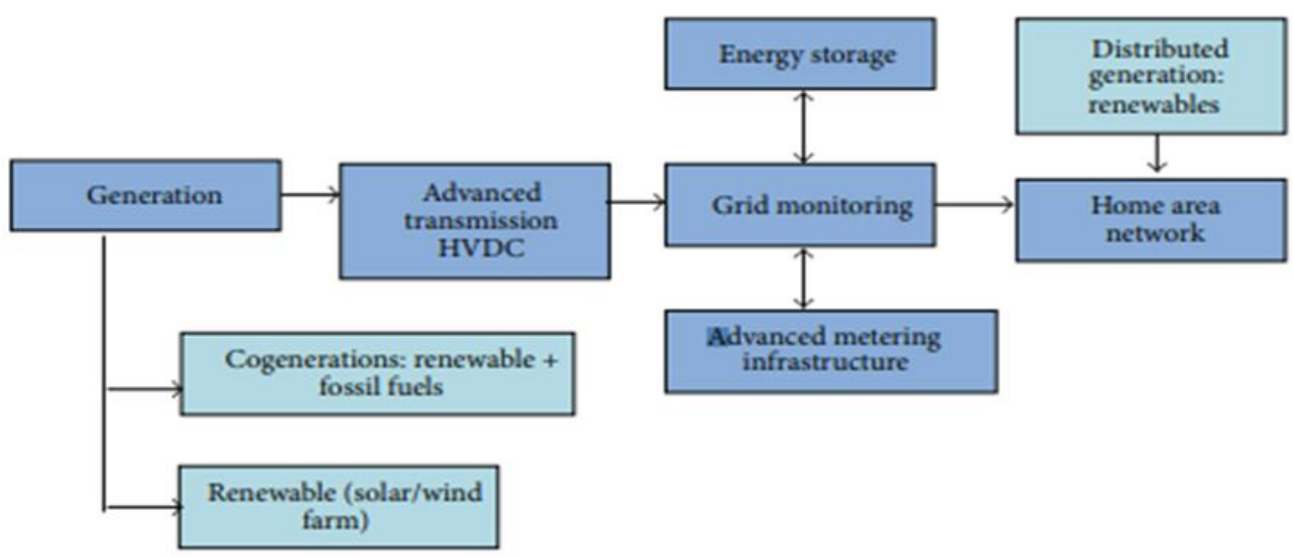

(b)

Figure 2. Smart Grid Concept (a) Pictorial view (b) Block diagram (Joy et al., 2013; SGA, 2011)

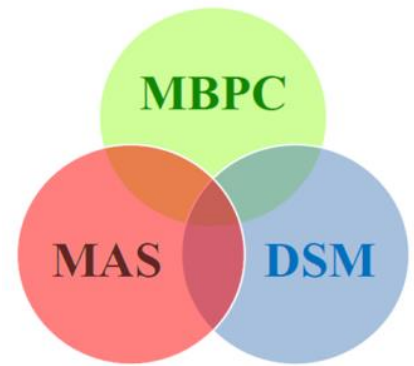

Figure 3. Venn diagram of Smart Grid Technologies

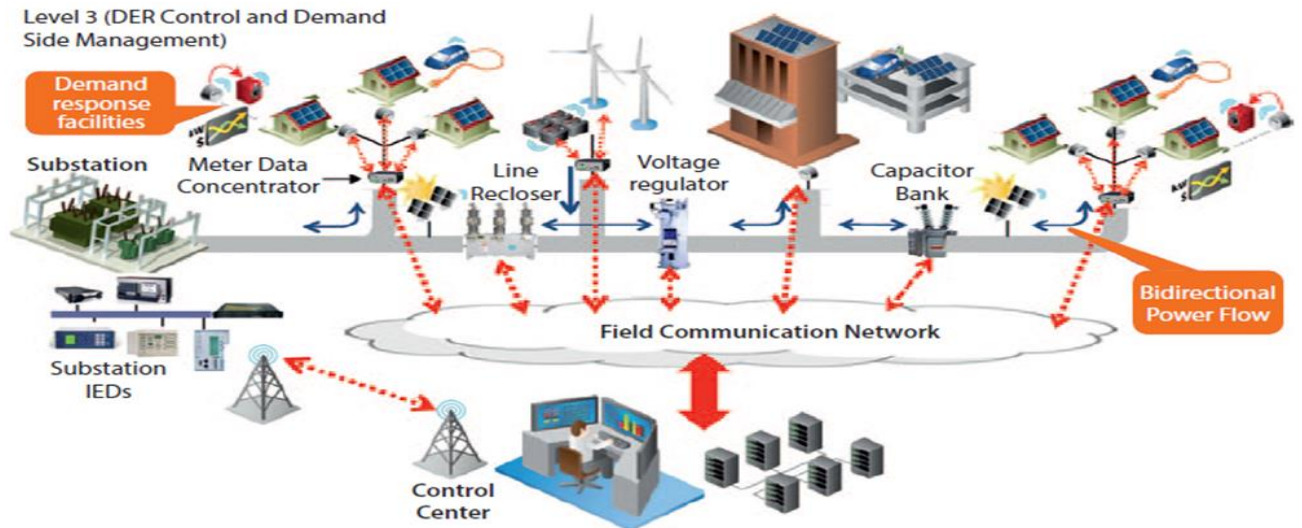

Figure 4. Grid modernisation (Madrigal et al., 2017) 


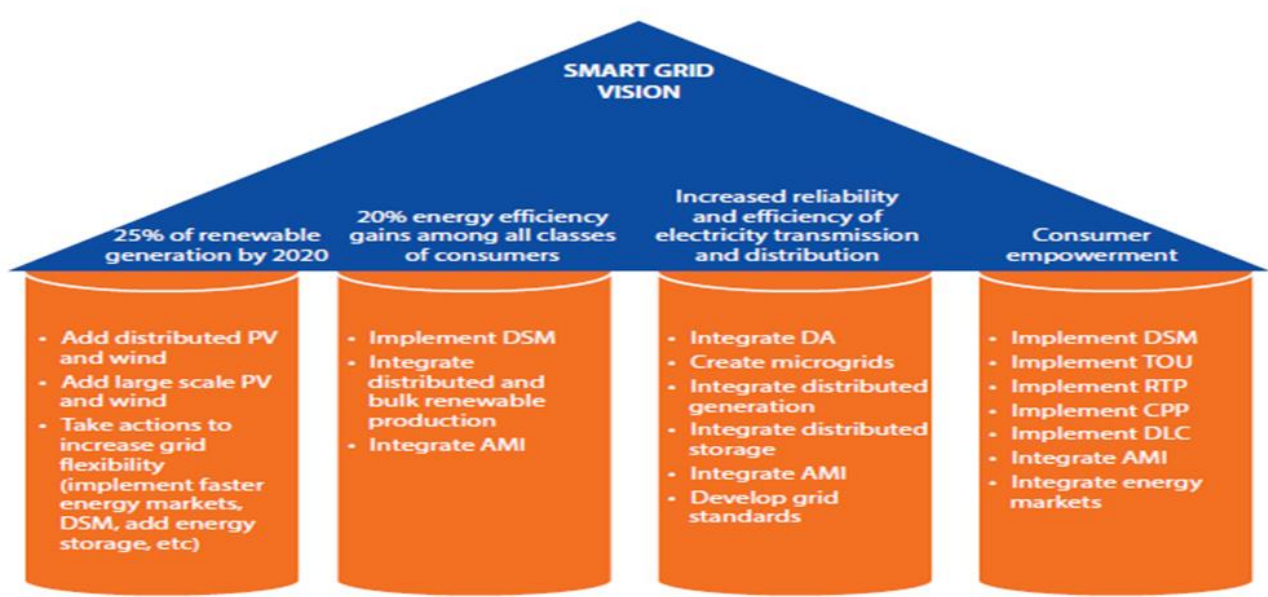

PV: Photovoltaic; DSM: Demand side management; AMI: Advanced metering infrastructure; DA: Distribution automation; TOU: Time of use; RTP: Real-time pricing; CPP: Critical peak pricing; DLC: Direct load control; RES: Renewable.

Figure 5. Smart Grid Vision and Its Pillars (Madrigal et al., 2017)

\subsection{Software/Abstractions and Simulation/Communication Based Approaches}

Silva et al. (2011) proposed how Supervisory Control and Data Acquisition/Distribution Management System (SCADA/DMS) should evolve to tackle new challenges, including new functionalities such as optimal network operations, voltage control and fault detection, system stability and validation of maintenance schemes in order to minimise operational costs and increase reliability. The paper then spots the ways how the configuration at the upper SCADA/DMS levels is built automatically based on the lower level models. Following the models, it reduces the overall configuration cost. A smart grids architecture was adopted but not implemented in a real-life situation.

Huang et al. (2012) provided a survey on state estimation (SE) in electric power grids and examines the impact of SE on the technological changes being suggested as a part of the smart grid development. The SE is a fundamental functionality to ensure smooth, reliable and secure operation of the power grids being that; SE at the transmission level has a long history. Then, further research and development of innovative SE schemes, including the distribution systems are needed to meet the new challenges presented by the future grid.

Guo et al. (2013) presented a comprehensive platform to overcome current challenges in smart grid related to real-time simulation. The simulation platform developed mimics both the power network as well as the communication network operations accurately which can also be used to evaluate various design and reconfiguration strategies for an actual smart grid. In fact, with the cooperation of advanced software and hardware, the communication of power network simulator and communication network simulator which is the platform developed is capable of simulating complex smart grid models with large numbers of highspeed switching devices at real time. At the end of the research, it was found out that communication system brings great benefits to the operation of new and different types of protection schemes and control. But actual or prototype was not implemented to test the validity of the platform.

Carvato (2015) presented a comparison of distinct policy and regulatory approaches of the European Union (EU) in relation to Brazil for the development of its smart metering frameworks. A comparative law analysis of the policies and mandatory market-driven rationale found in the EU in regard to Brazil's regulatory and voluntary consumer-driven approaches in order to learn and discover what to be transferred to Brazil to enhance its timid approaches in relation to roll-out of smart meters as compared to the EU; especially because it is not enshrined in any public policy, be it related to combating climate change or to smart grid deployment more generally. The comparison of their distinct regulation approaches and stages of development with respect to smart metering deployment has shown that the EU is ahead of Brazil. Consequently, it is ultimately advisable that Brazil should learn from what has been done in the EU, with respect to building a general framework for smarter grids and smart meters' deployment.

Karuppiah et al. (2005) proposed a strategy for a sensor targeting that is aware of the information generating processes in the environment. The ideas are based on deployment of scalable information gathering and data observations system that will lead to automatic context derivation and resource management policies in sensor networks. A novel strategy for managing redundant camera resources using policies that are derived automatically from models of the environment of the camera and the camera configurations were used; and the models of motion dynamics in the scene and the camera network 
configuration steer the policies to provide robust tracking in the system. The policies derived are the Dynamic switching policy (D-policy) and the static switching policy (Q-policy) which perform the functions of minimizing the number of context switches by allowing for some degradation in the triangulation quality and greedy on the triangulation quality respectively. From the experimental test results of the derived policies, it showed that the D-policy minimises the number of context switches by allowing for some degradation in the triangulation quality when compared to the Q-policy.

Cecati (2010) provided the overview of a smart grid concept. The various sections of smart grid and their functionalities; the preferred communication and monitoring medium were highlighted. The use of computational intelligence methods, intelligent equipment and smart routing algorithms to achieved smart grid results were stated. Ullah et al. (2013) presented different energy consumption scheduling schemes to meet the peak load demand and reduce the monetary cost. Residential load controlling techniques are employed for efficient consumption of electricity in residential buildings like homes and offices which the load demand curve shows that there is huge difference between the demand of peak hours and off-peak hours. The load controlling techniques shift some specific load from peak hour to off-peak hour and consequently, helps in making the demand curve smooth. The results showed that out of the various schemes applied, scheme 1: DSM was found more efficient when compared with other schemes and it reduces the peak load up to $66.66 \%$.

Samadi et al. (2012) developed a novel pricing method for demand-side management (DSM) to encourage efficient energy consumption among users to achieve certain social objectives in the future smart grid. Since the social objectives computational complexity is difficult to achieve, a top-down control approach was derived to tackle the emerging challenges and; based on the social objectives model, the paper suggested a Vickery-Clark Groves (VCG) mechanism which aims to maximize the social welfare that aggregate utility functions of all users while minimising the total energy cost. The important properties of the suggested VCG method (mechanism) for demand-side management such as: efficiency, user truthfulness and nonnegative transfer were verified. Tremendously, the simulation results showed that the suggested VCG mechanism improves the performance of the system by encouraging users to reduce their power consumption and shift their loads to off-peak hour while maximizing social welfare. In addition, the simulation results confirmed that the proposed pricing method benefit both the users and utility companies.

Rumley et al. (2008) presented an alternative approach based on Multi-Agent System (MAS) for implementing a distributed control algorithm. A method of distributed generation operations in distribution network and control schemes using the multi-agent system that was suggested. This method relieves congestions while feeding electrical loads by an on-line assessments of a new network configuration. The reconfiguration was then done within the specified technical and operational constraints and also considering the minimum switching operations. The simulation results of the case study carried-out showed that the scheme can decongest the feeders by balancing the feeders load. But the scheme suffers strong limitations, in particular since agents are not synchronised and only local search was achieved.

Brown et al. (2010) described some elements of design and operational philosophies for a smart distribution system. Their emphasis was automation of the design, reliability enhancement, operations and reconfiguration after a disturbance; and the method adopted was an algorithm for redesigning radial distribution systems into partially networked systems. This algorithm uses a priori information regarding location and rating of renewable distributed generators (RDGs) installations and a new heuristic algorithm called the sequential feeder approach was used to solve the stated constrained optimisation problem. The sequential feeder approach was applied also to ES-I as a case study and the results showed that the reliability of an automated distribution system may make the cost and benefit analysis of alternative configurations favour "smart" design and the classical reliability indices such as ASAI may also be improved. Figure 6 illustrates sector-wide policies and goals of smart grid in the power sector while Figure 7 illustrates the distribution automation system in smart grid to manage outages with others smart feature embedded in the power system. 


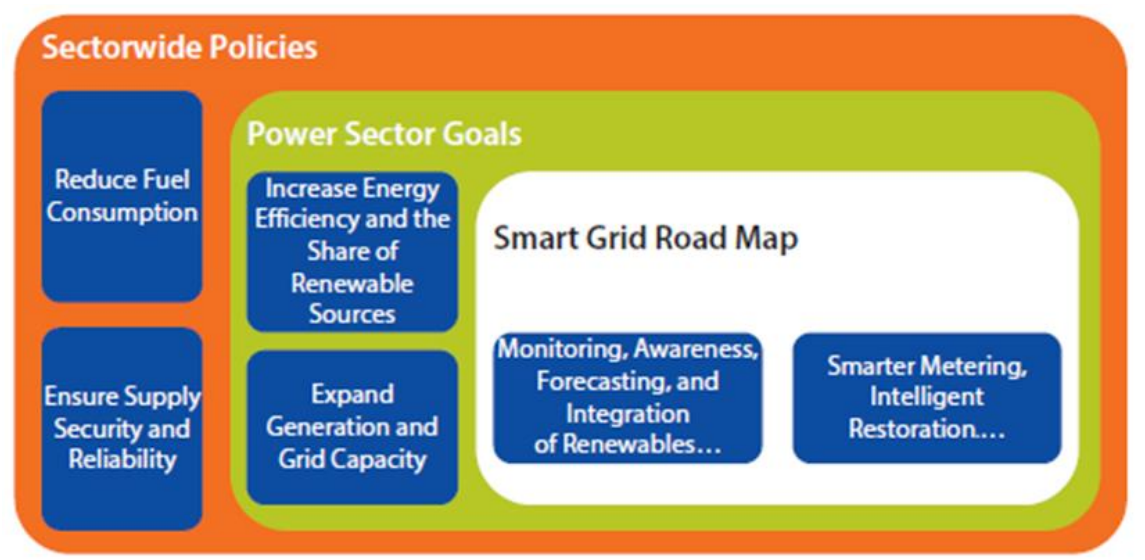

Figure 6. The Role of Smart Grid in the Overall Electricity Sector (Madrigal et al., 2017)

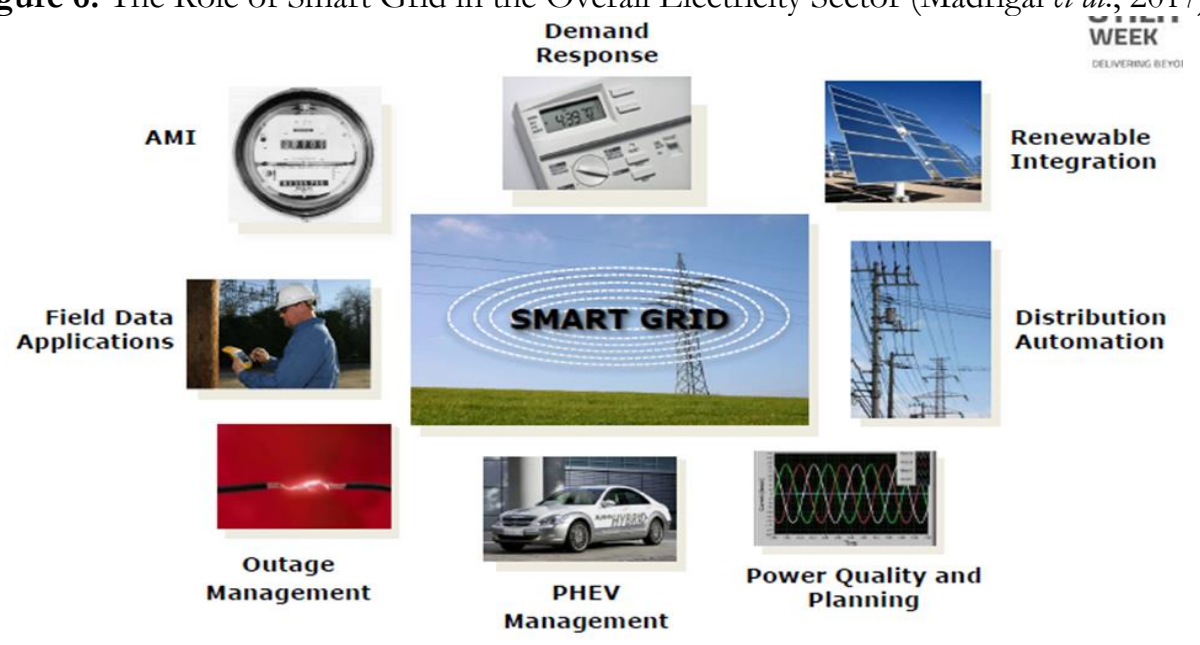

Figure 7. Smart Grid Outage Management System (Folly, 2013)

Additionally, Ayan \& Turkay (2017) investigated the energy demand profiles for residential sector and carried-out overview of smart plugs and smart thermostats that are currently in market and how consumers/users can use them effectively. Simulations were carried-out to show the effect of controlling deferrable loads in the residential sector and how efficient the smart plugs and thermostats can manage the use of energy over manual and programmable plugs and also, the efficient use of a combi boiler at home. The results of the simulations showed that some residential loads were shifted from peak hours to off-peak hours for thirty (30) days through the use of smart plugs and thermostats; and there was a reduction in peak demand up to $33.24 \%$ and also, the result showed how combi boiler can be used economically and efficiently.

Bernardon et al. (2010) developed a methodology to re-establish the electrical energy supply by using remote-controlled switches and also, regarding the validation of the technical viability for distribution networks reconfiguration in real time by means of computational simulations and applying the Smart Grid concept. Bell-Zadeh method, which uses fuzzy algorithm was applied and the algorithm was used to choose the option for load transfers using remote-controlled switches after contingencies which was based on multicriteria decision making methods. The algorithm proving to be effective for resolving issues involving multicriteria inputs. The reduction of approximately $30 \%$ in the annual SAIDI was estimated, faults concerning the primary network of the feeder in the performance verification of the suggested method in the case studies in the concession area of AES Sul, power utility in Brazil. The case studies with real data from the utilities was conducted to evaluate the performance of the software developed, and the results showed satisfactory.

Dam et al. (2008) proposed an intelligent module for performing automated demand response (DR) at the customer side. The suggested demand response (DR) module was designed based on the expert systems theory, and in which different modules were designed to take the market rates as well as the local load management policy of the customer into account in order to make a decision in reducing load. The expert system engines were used to receive the external information (DR signal from the utility market rates) which run them against local load management policy and consequently make the final decision so 
as to accept or reject a DR request by the utility. Different scenarios were considered and the intelligent engine was able to meet up with the requirements of the different scenarios depending on the DR policy that customer has subscribed to. The validity of the proposed intelligent algorithm was tested using the RTLab real-time experimental setup and the results showed that energy savings of $40 \%$ for customer 1 and $12 \%$ for customer 3 .

Khan et al. (2015) developed a generic demand-side management (G-DSM) model based on generic algorithm (GA) for residential users to reduce peak-to-average ratio (PAR), total energy cost and waiting time of appliances (WTA). The GA finds out the optimal schedule of each appliances for energy management controller unit (EMCU) by selecting the suitable starting time for each appliance and respecting the real-time pricing (RTP) and the power capacity constraints. The G_DSM model performance was evaluated and compared for different loads with load management through EMCU and without load management. The simulation results showed that the suggested G-DSM model minimise the individual user cost by $39.39 \%$ and twenty (20) users cost by $45.85 \%$, while the reduction in PAR for single user and twenty (20) users were $17.17 \%$ and $45.24 \%$ respectively. Also, the relationship of WTA with electricity cost was demonstrated as well.

Iqbal et al. (2016) proposed an efficient ECG optimisation model that include energy consumption minimisation, energy consumption cost minimisation and energy generation cost optimisation for smart home energy management based on demand-side management (DSM). The ECG model was used for balancing the total energy generation cost and two main types of energy sources: Iceg and Icd which are named macro-grid and micro-grid for smart home appliances. The simulation results showed that the suggested model and ECG algorithm balanced the energy consumption with the supply and; reduces both types of cost as compared to the results without ECG model. Figure 8 gives detailed description of demand response management system in residential, C\&I and aggregation customers in the power systems as described in the respective literature survey.

Guo et al. (2010) outlined the functionality of the Australia's Commonwealth Scientific and Industrial Research Organisation (CSIRO) multi-agent based simulation environment called the Utility Simulation Tool (UST) that are used to model different automated demand-side management (DSM) strategies and their effect on the environment, economics and human satisfaction. The UST is a software that can compare the effectiveness of different DSM strategies such as the Direct Load Control (DLC) and Price Based Control (PBC). The UST allows user to simulate consumer responses based on household building model, behavioural model and electricity market model. Different scenarios were simulated experimentally and the results using the UST showed that the energy consumption under different assumptions and control strategies, and the dissatisfaction level of households have impact on the energy consumption.

Giusti et al. (2014) developed a realistic micro-simulation environment accounting for the behavioural of residents, dispatchable and non-dispatchable household loads and the effects on the distribution network. The simulation environment and the optimisation algorithm are implemented in the Java while the optimisation sub-problems are solved using GLPK, an open source solver for linear programme. This work was built on the micro-simulation and optimisation framework developed by Salani et al. (2011) for fully decentralised demand-side management (DSM) of household loads in distribution networks. In this work, a generic model of communication among household controller's not tied to any specific technology and is based on the partitioning of the households in a number of groups (neighbourhoods) were considered. And in the approach, each controller belongs to a certain neighbourhoods which depends on the topology of the low voltage (LV) distribution network. Different scenarios were carried-out and the simulation results from extensive experiments observed that even communication neighbourhoods constituted by as few as three to four $(3-4)$ households were efficient to effectively stabilise the aggregate network profile, with minimal bandwidth consumption. $T$ was observed that, effective load flattening can be achieved with minimal requirement in terms of communication infrastructure and transmitted information. Figure 8 depicts the demand response management system in the network

Dethlefs et al. (2015) proposed a distributed Ant Colony based self-optimisation approach for demandside management (DSM). The implementation of the Ant Colony System (ACS) as a meta-heuristic for the optimization as well as the developed distribution concept of the algorithm were expatiated. The distributed algorithm was integrated as a cooperative planning step into the MAPE-K feedback loop from the automatic computing approach. A self-optimising DSM system that is able to adapt its day-ahead planning to sudden environmental changes was realised. A case study was simulated in order to match generation data and the residential demand. The results showed how the system was able to adapt its scheduled load in a self-optimising fashion to the changing environmental condition, arising in an optimised load scheduled. 


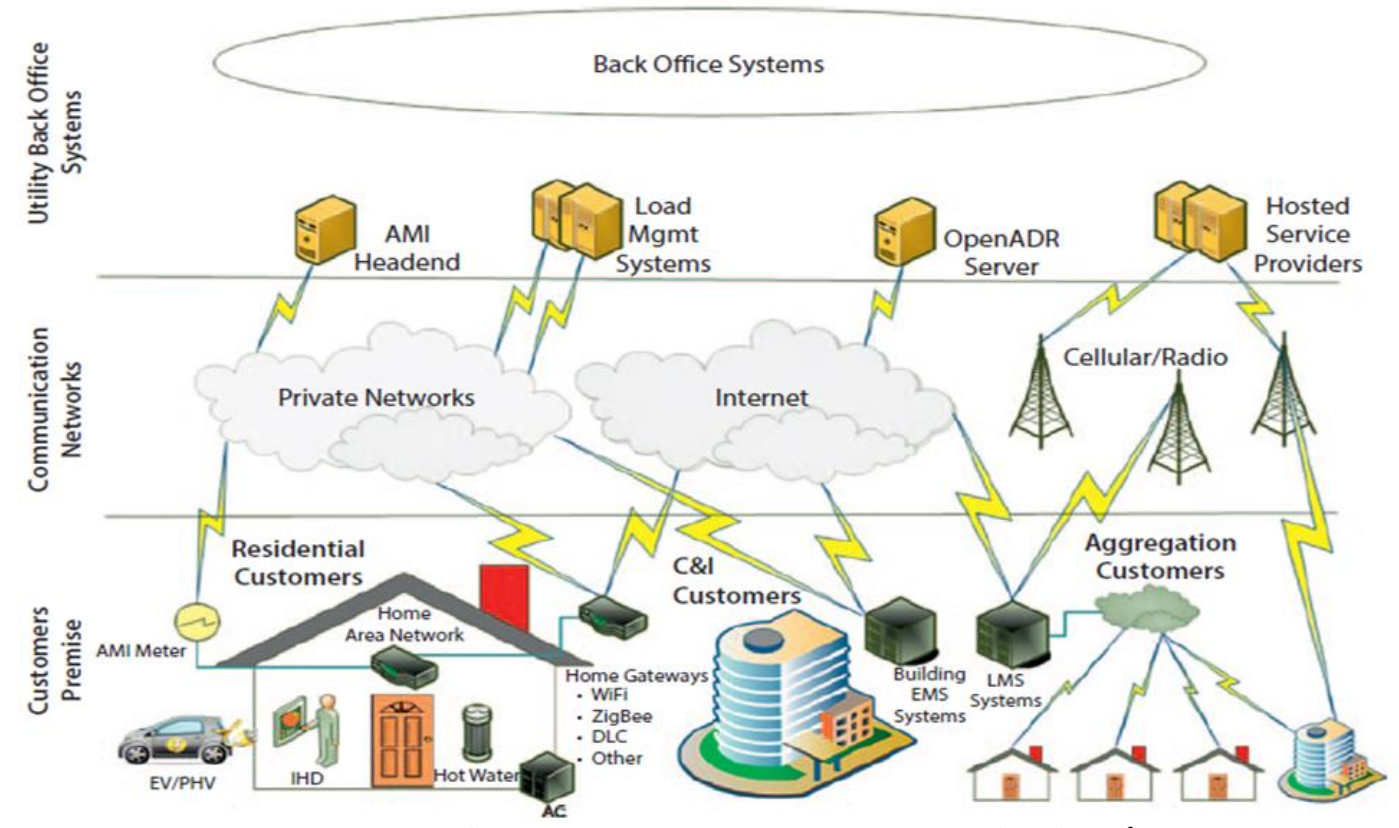

Figure 8. Demand Response Management System (Madrigal et al., 2017)

Sakthivel \& Winston (2014) presented a methodology for optimal operation of smart grid to minimise the power flow fluctuations and the DC controllable loads in residential houses. Various optimization techniques were applied to minimise power flow fluctuations in smart grid and the neural network optimization technique which determines the operation method of controllable loads in order to suppress interconnection point; power flow fluctuation based on information obtained by the communications infrastructure that was applied. The power consumption in smart grid was smoothed by achieving the neutral network, which suppresses the impact of PV against the power system. Consequently, high quality power supply is expected and reduced cost by cooperative control in smart grid.

Dolezilek \& Schweitzer (2011) described the practical application of smart grid technologies as applicable to power systems. The focus of the paper was on distribution level protection and automation techniques, which was illustrated with real world scenarios. The widely use of distribution automation systems (DASs) and intelligent electronics devices (IEDs) in electric power systems as the building blocks of a smarter and more reliable grid is also widely expatiated in the paper. The paper then described various smart grid technologies applied by various utility companies such as AEP, PSE \& P and Xcel Energy which apply these technologies in different ways to meet their reliability goals; especially Xcel Energy which places additional focus on leveraging smart technologies to better inform its customers and reduce overall carbon emissions. Finally, the measurable benefits of each application demonstrate a tangible return on investment via documented business decision-making information. But the article didn't explain the security challenges that may arise with the use of these technologies. Figure 9 illustrates monitoring and control of smart grid in power systems.

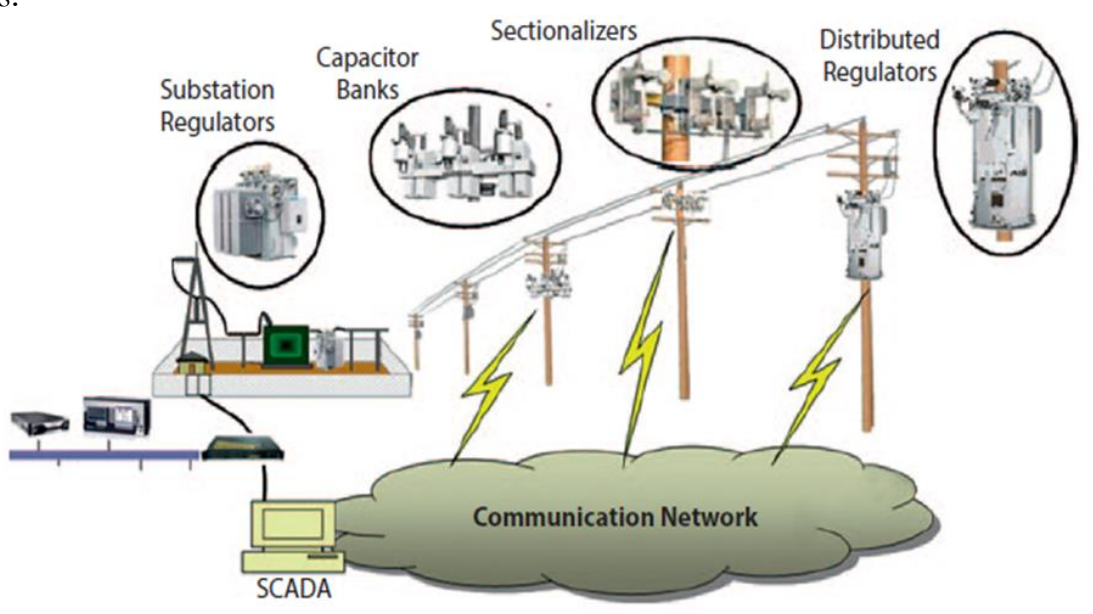

Figure 9. Vision for Data Monitoring and Control (McGranaghan \& Uluski, 2012) 


\subsection{Hybrid Based Approaches}

Gholinejad et al. (2014) presented a new approach by rearranging the network which is aimed at reducing losses and improving load balancing in the distribution networks. The author tried to combine the simulation and computational methods to introduce a new face to smart grid system configuration and to do this, they merged the computational methods with a powerful algorithm and with the strongest software. The algorithm adopted was ant colony algorithm which has the capacity to make a wide search space and MATLAB, DigSilent and EMTP software were used for the modelling. The results of the numerical modelling application showed that a meaningful energy saving was achieved, loss reduction and load balancing in the feeder.

Rogers \& Polak (2013) developed a specially-tailored dynamic polynomial (DP) algorithms for efficiently solving the pairs sum (PS), Minimax PS (MPS), and minimax Distance (MD) models in polynomial time complexity similar to those available for solving the classical IP optimisation models for shortest path problems. Additionally, a more efficient greedy algorithm that can be proven sufficient for solving chained sum (CS) model to optimality was also developed. The DP and greedy algorithms are polynomially-bounded for large instances while the Coin-OR struggled with models for small instances. The IP models were populated with a real-world dataset of electricity usage for ninety-three (93) buildings, and the solutions and run-time attained by conventional optimisation software were compared with those by dynamic programming, or by greedy algorithm applicable to one of the models, that run in the polynomial time. The results provide time-of-use segments that an electricity utility may employ for selective pricing for peak and off-peak time periods to influence the demand for the purpose of load levelling.

He \& Blum (2011) proposed a method that recognised changes in power system by employing hypothetical testing to detect changes in the state space model for the system. The time evolution of the smart grid system was modelled by a discrete-time linear state space modelling using some frequently made approximations; and the fault detection which was described by changes in the system matrices of the state space model, which was improved by the new developed locally optimum (LO) test and it was utilised to improve the performance for detecting small changes. Due to the drawback of LO test to detect large changes, a combination was made between a generalised likelihood ratio (GLR) test and locally optimum unknown direction (LOUD) test or locally optimum estimated direction (LOED) test to form new locally optimum tests called LOUD-GLR test or LOED-GLR test as an improved test method. It was showed that the new LO tests, which are LOUD test and LOED test were favourable for detecting small changes with unknown directions, while the improved test methods which is the combination test of LOUD-GLR test and LOED-GLR test have satisfactory performance for the detection of both small and large changes.

From the literature survey in this research, it has been shown that smart grid is an enhancer that enhances the smartness of the grid to improve the power quality, voltage profile, and reliability and to minimise power losses in the network, etc. Smart grid also enhances the energy management system of the grid thereby reducing the blackout areas of the network and, the frequent outages, fault sections and locations of faults in the network. It can be said that the smart grid is an enabler and the incorporation of the smart features of the smart grid into the Nigeria traditional or conventional grid will modernise and enhance the performance and operation of the grid to give an efficient and reliable energy services to the Nigerian energy consumers like any other grid of the future in developed countries called the smart grid. Some of the smart features of the smart grid technologies were already highlighted in the previous section.

\section{Impact of Smart Grid on Distribution Network Reliability}

The smart grids use composition and communication to improve the efficiency and reliability of the distribution network. The integration of smart features in the complex physical systems results in cyberphysical systems (CPSs). The modern critical infrastructure systems such as intelligent grids, intelligent water distribution networks, or health information networks, are good example of CPSs that exhibit significant dependence on the cyber components (Marashi \& Sarvestani, 2014). The application of digital technologies such as: microprocessor-based measurement and control, two-way communication, computation, data storage and information systems to the traditional existing network is expected to improve the reliability, security, interoperability and efficiency of critical infrastructures, while reducing environment influences and promoting economic growth (Marashi \& Sarvestani, 2014; NIST, 2010). Improved reliability is a key potential benefit of smart grid on power networks, especially the distribution system. Hence, reliability improvement includes improving the security, resiliency, risk, robustness and vulnerability of the network, since reliability encompasses the aforementioned. 
The impact of smart grid on conventional distribution network reliability can be measured using the distribution reliability indices or metrics such as the system average Interruption Frequency Index (SAIFI) and the System Average Interruption Duration Index (SAIDI). These indices measure the level of retail service in the distribution network in terms of the average frequency of outages per customer in a period of one year. Also, other customer-oriented reliability indices are (Kumar et al., 2013): The Customer Average Interruption Frequency Index (CAIFI) which is helpful in recognising sequential trends in the distribution network. Another customer-oriented metrics is the Customer Average Interruption Duration Index (CAIDI), which is defined as the average time to restore service to customer(s) in occurrence of outage(s). The Average Service Availability Index (ASAI) is the ratio of the total number of customer hours that service was available during a given period of the total customer hours demanded. For the impact of smart grid on distribution network reliability to be evidential, the issues with security, vulnerability and the network resiliency must be improved upon. In other words, emerging issues and challenges evolving from the application of Smart Meter System (Smart Grid) to power systems must be addressed if the benefit of smart grid on the system's reliability is to be adequately realised.

\section{Emerging Issues and Challenges of Smart Grid in Electric Power Distribution System}

The application of smart grid or smart meter system to existing (traditional) grid or developing one poses a lot of issues and challenges. But, "in view of the technical advantages and enhancements to the operation capability, the integration of the smart grid stands as a valuable solution in managing the existing grid which cannot be overemphasised. Consequently, the design, deployment, operation and maintenance of the smart meter system involve many issues and challenges as mentioned earlier to the grid in terms of vulnerability, cyber-attacks, resilience, lack of awareness, skilled and knowledgeable man-power, data privacy etc. The following section will highlight some of the common emerging issues and challenges in smart grid deployment:

(a) Vulnerability of Smart Grid: The smart grid system brings enhancements and improve the capabilities of the traditional electric power network by making it more complex and vulnerable to different types of attacks due to the complexity of smart meter and; information and communication techniques introduced to the grid. These vulnerabilities might allow attackers to access the network, break the confidentiality and the integrity of the transmitted data and make the service unavailable. Some of the vulnerabilities of the network are (SGS, 2018): customer security of data, more number of smart devices in the network, physical security challenges, lifetime of power system, implicit trust between traditional power devices, Different Team's backgrounds, using Internal Protocol (IP) and commercial off-the-shelf hardware and software, too many stakeholders etc.

(b) Cyber Security and Data Privacy in Smart Grid: As the conventional power system transit from analogue to digital or two-communication oriented electric grid with modern facilities, it comes with the challenge of communication security and data management; as digital networks are prone to malicious attacks from software hackers; then, security becomes the issue to be addressed in the network (Kaushal, 2011). Also, concern on invasion of privacy and security of personal consumption data arises. The data collected from the consumption information could provide a significant insight of consumers' behaviour and preferences. This valuable information could be abused if correct protocols and security measures are not adhered to (Kaushal, 2011).

(c) Lack of Awareness of Smart Grid: The consumers' level of understanding about how electric energy is being delivered to their households is low. Consequently, the awareness of the energy consumers about smart grid is nearly zero and this may affect the acceptability of the smart grid system. Thus, before going forward in smart grid initiative and its deployment in the power network, the consumers should have been educated about the functionality and the consumers' side benefit of smart grid implementation in the network.

(d) Skilled and Knowledgeable Man-Power: As the traditional power network transit to smart grid network, there will be a demand of new technical skills that the conventional power grid skilled manpower can't bridge the gap, especially in the areas of data management and decision-making support. Hence, this high technical skilled man-power wound have bridged (addressed) the gap of new technical challenges posed by the smart grid network and it needs to be made available for smooth functioning of the network.

In totality, Depuru et al. (2011), illustrated various issues and challenges in design, deployment, utilization and maintenance of the Smart Meter System (Smart Grid) in electric power network into three categories as shown in Figures $10-12$. 


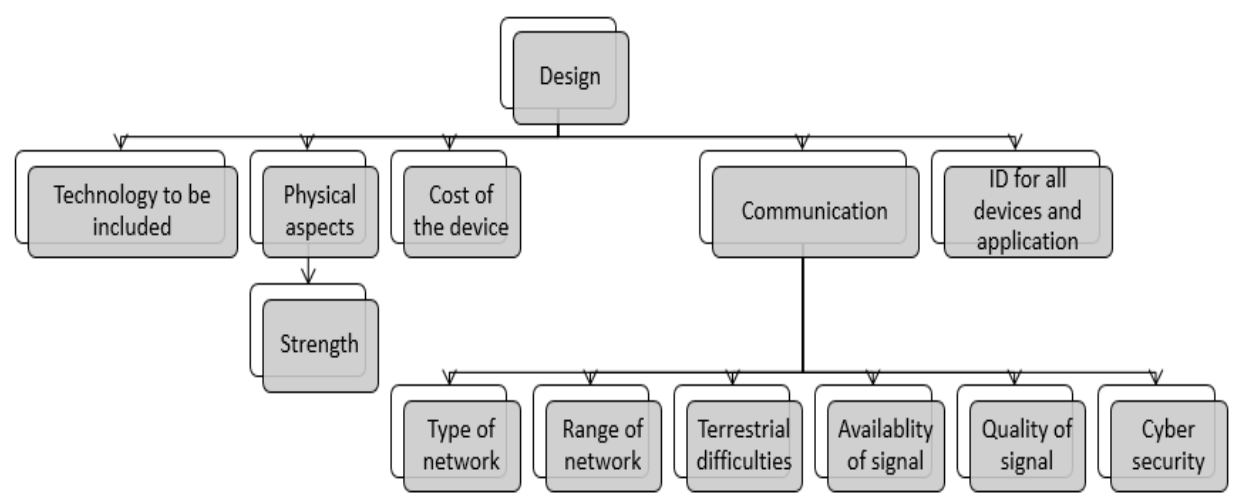

Figure 10. Design Issues for a Smart Meter System (Depuru et al., 2011)

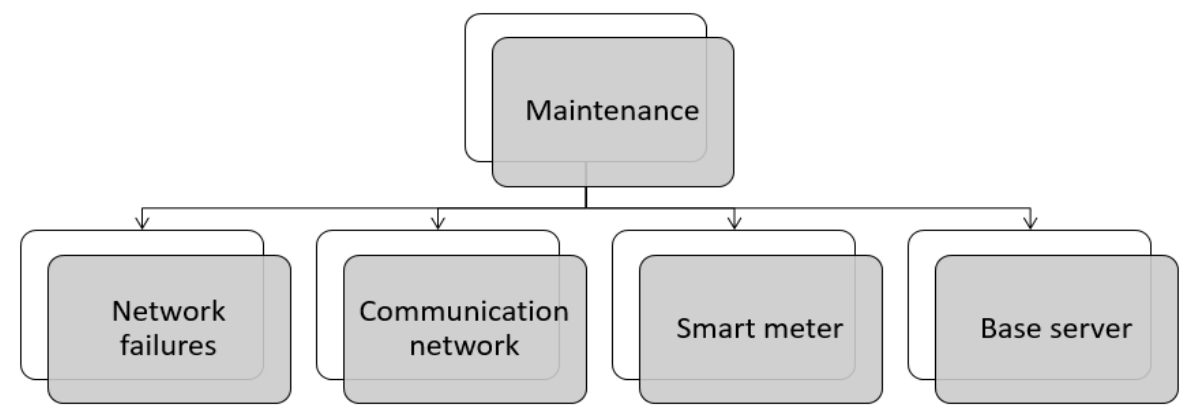

Figure 11. Maintenance Issues for Smart Meter System (Depuru et al., 2011)

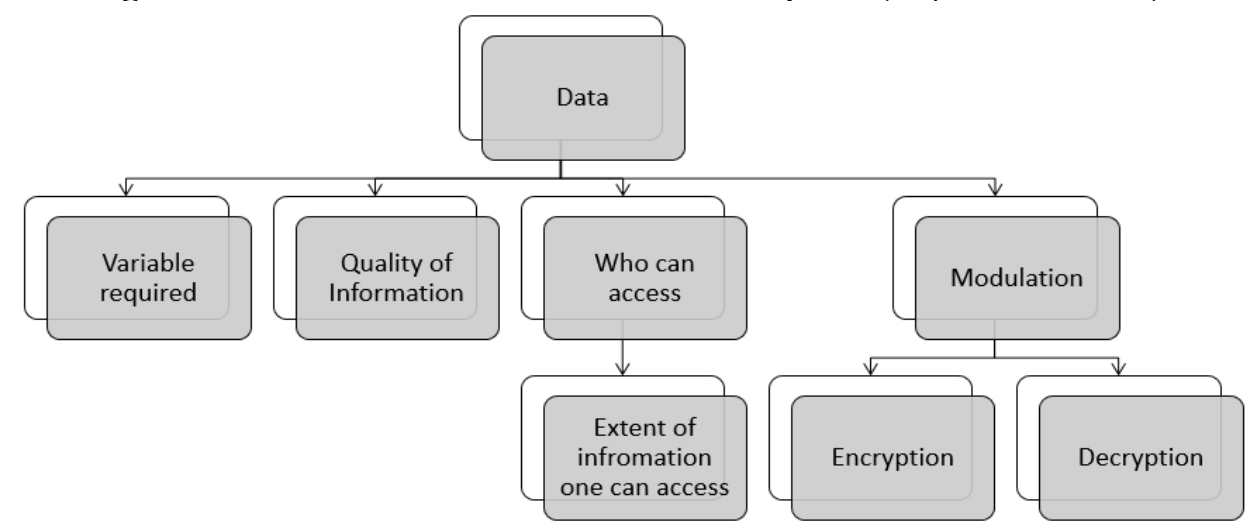

Figure 12. Challenges with Data Transfer for Smart Meter-System (Depuru et al., 2011)

Figure 10 was described as a diagram that illustrated several major design issues and constrains including the extent of technology to be included; this technology might include the kind of billing, control systems related software and other metering technology, the physical safety aspect such as positioning of the smart meter and physical strength of the structure that houses the smart meter components. He went on to say that, after deploying the required infrastructure, the next major encounter would be maintaining all the components of the network in case of any failure which Figure 11 illustrated. Besides these issues, dealing with the data transfer in the network could be another major issue which Figure 12 described.

\section{Conclusion}

In this paper, attempt has been made to carry-out a survey of Smart Grid Systems (SGSs) on electric power distribution network and its impact on reliability of the system. The paper also stresses the importance of smart grid, smart techniques and their features in relation to the modernisation of the conventional electric grid. The transition of the current conventional electric grid to smart grid system is one of the key decisions to network reliability, efficiency and resilience goals in the system. Furthermore, the work encapsulates the emerging issues and challenges in smart networks and the reliability metrics in the electric power distribution network. 


\section{Conflict of Interests}

The authors declare that there is no conflict of interests regarding the publication of this paper.

\section{References}

Akpojedje, F. O. Ogujor, E. A., \& Folorunso, O. (2018a). Influence of Optimal Network reconfiguration of Electric Power Distribution Feeders on Power Loss Minimisation: A Comprehensive Review. IOSR Journal of Electrical and Electronics Engineering, 13(2): $42-56$.

Akpojedje, F. O., Ogujor, E. A., \& Folorunso, O. (2018b). A Comprehensive Review of Optimal Demand Side Management and Its Influence on Enhancing Distribution Network Congestion Management. International Journal of Research in Engineering and Technology, 7(9): $42-56$.

Ayan, O., \& Turkey, B. E. (2017). Smart Home Energy Management Technologies Based on Demand Side Management and a Review of Smart Plugs with Smart Thermostats. Istanbul technical University, Turkey, 1-6.

Bernardon, D. P., Garcia, V. J., Sperandio, M., Russi, J. L., Daza, E. F. B., \& Comassetto, L. (2010). Smart Grid Concept Applied to Distribution Networks Operation. Proceedings of the Universities Power Engineering Conference, doi: 10.1109/UPEC.2012.6398655

Brown, H. E., \& Suryanarayanan, S. (2009). A Survey Seeking a Definition of a Smart Distribution system. Published in 41st North American Power Symposium, doi:10.1109/NAPS.2009.5484078

Brown, H., Haughton, D. A., Heydt, G. T., \& Suryanarayanan, S. (2010). Some Elements of Design and Operation of a Smart Distribution System. Retrieved from http://pserc-smart-dsys.pbworks.com/f/SmartDistribSystemsTD10.pdf (10th of May, 2019)

Cardenas, J., De-Vinaspre, A. L., Argandona, R., \& Farooqui, H. (2012). The Next Generation of Smart Substation: Challenges and Possibilities. CIGRE, 2012, $1-9$. http//www.cigre.org

Carvato, P. (2015). Smart Metering Deployment in Brazil. $7^{\text {th }}$ International Conference on Sustainability in Energy and Buildings, Energy Procedia, 360 - 369

Cecati, C. (2010). An Overview on the Smart Grid Concept. In: Proceedings of the 36th annual conference of the IEEE Industrial Electronics Society, IECON 2010, 3322-3327.

Dam, Q. B., Mohaghehi, S., \& Stoupis, J. (2008). Intelligent Demand Response Scheme for Customer Side Load Management. IEEE Energy 2030, Atlanta, GA USA, 17 - 18th September.

Depuru, S. S. S. R., Wang, L., Devabhktuni, V., \& Gudi, N. (2011). Smart Meters for Power Grid-Challenges, Issues, Advantages and Status. IEEE, $1-7$.

Dethlefs, T., Preisler, T., \& Renz, W. (2015). Ant-Colony Based Self-Optimization for Demand Side Management. E-World Energy \& Water, Proceedings of Smarter Europe, $1-8$.

Dolezilek, D. J., \& Schweitzer, S. (2011). Practical Applications of Smart Grid Technologies. Presented at Saudi Arabia Smart Grid 2013, Jeddah, Saudi Arabia. Previously Published in SEL Journal of Reliable Power, 2(1).

Folly, K. A. (2013). Challenges in Implementing Smart Grid Technologies in Africa. 13 $3^{\text {Th }}$ Annual African Utility Weeks, University of Cape Town, 14 - 15 May, Cape Town, South Africa. www. African-utility-week.com

Gholinejad, H., Mousavi Takami, K., Mousavi Takami, A., \& Dahlquist, E. (2014). To Promote Electricity Smart Grid Performances by Numerical Modelling Applications. In: Alireza Kolai, Kim Sorensen \& Mads Pagh Nielsen (ed.), Proceedings of the 55th Conference on Simulation and Modelling: modelling, Simulation and Optimization, 347 - 355. Linloping: Linkoping University Electronic Press.

Giusti, A., Di-Caro, G. A., Rizzoli, A. E., \& Gambardella, L. M. (2014). Restricted Neighborhood Communication Improves Decentralized Demand Side Load Management. Dalle Molle Institute for Artificial Intelligence (IDSIA)-Lugano, Switzerland, $1-10$.

Guo, F., Herrera, L., Murawski, R., Inoa, E., Wang, C. L., Beauchamp, P., Ekici, E., \& Wang, J. (2013). Comprehensive Real-Time Simulation of the Smart Grid, IEEE Transactions on Industry Applications, 49(2): 899 - 908.

Guo, N., \& Qin, L. (2014). Reliable Intelligent Distribution Network Structure. Journal of Clean energy Technologies, 2(1): 69 72.

Guo, Y., Zeman, A., \& Li, R. (2010). Utility Simulation Tool for Automated Energy Demand Side Management. Autonomous Systems Laboratory, CSIRO ICT Centre, Marsfield, 37 - 44.

Hatziargyriou, N., Asano, H., Irawani, R., \& Marnay, C., (2007). Micro-grids: An Overview of Ongoing research, Development and Demonstration Projects. IEEE Power \& Energy Magazine, Ernest Orlando Lowarence Berkely National Laboratory, 76 - 94.

He, Q., \& Blum, S. R. (2011). New Hypothesis Testing-Based Methods for Fault Detection for Smart Grid Systems. 45th Conference on Information Sciences and Systems in Baltimore, MD, USA.

Huang, Y. F., Werner, S., Huang, J., Kashyap, N., \& Gupta, V. (2012). State Estimation in Electric Power Grids: Meeting New Challenges Presented by the Requirements of the Future Grid. IEEE Signal Processing Magazine, 20: 33 - 43.

Iqbal, Z., Javaid, N., Khan, M. R., Khan, F. A., Khan, Z. A., \& Qasim, U. (2016). A Smart Home Energy Management Strategy Based on Demand Side Management. 2016 IEEE 30th International Conference on Advanced Information Networking and Applications, $858-862$.

Joy, J., Jasmin, E. A., \& John, V. R. (2013). Challenges of Smart Grid. International Journal of Advanced Research in Electrical, Electronics and Instrumentation Engineering, 2(3): 976 - 981.

Karuppiah, D., Grupen, R. A., \& Riseman, E. (2005). Smart Resource Reconfiguration by Exploiting Dynamics in Perceptual Tasks.

Kaushal, R. (2011). Challenges of Implementing Smart Grids in India. Retrieved from https://www.greatlakes.edu.in/gurgaon/sites/default/files/SMAR_GRID_CHALLENGES.pdf (10 th of May, 2019) 
Khan, M. A., Javaid, N., Mahmood, A., Khan, Z. A., \& Alrajeh, N. (2015). A Generic Demand Side Management Model for Grid. International Journal of Energy Research, 954 - 964.

Kumar, N. M. G., Baju, P. S., \& Venkatesh, P. (2013). Reliability Indices Evaluation of a Real Time Rural Radial Distribution feeder. IOSR-Journal of Electrical and Electronics Engineering, 5(6): 1- 15.

Liserre, M., Sauter, T., \& Hung, J. H. (2010). Future Energy Systems. IEEE Industrial Electronics Magazine.

Madrigal, Marcelino, Robert Uluski, and Kwawu Mensan Gaba (2017). Practical Guidance for Defining a Smart Grid Modernization Strategy: The Case of Distribution. Revised Edition. World Bank Studies. Washington, DC: World Bank. doi:10.1596/9781-4648-1054-1. License: Creative Commons Attribution CC BY 3.0 IGO.

Marashi, K., \& Sarvestani, S. S. (2014). Towards Comprehensive modelling of Reliability for Smart Grids: requirements and Challenges. 2014 IEEE 15th International Symposium on High-Assurance Systems Engineering, 105 - 112.

McGranaghan, M., \& Uluski, R. (2012). Development of the Smart Distribution System. Presented to the International Conference on Electricity Distribution (CIRED) Conference, Frankfurt Germany.

Meyer, G. G., Yeh, Y. G., \& Tsai, M. S. (2012). Smart Devices for Demand Side Power Consumption Management. 2012 AASRI Conference on power and Energy Systems, AASRI Procedia, 1 - 6.

Mohassel, R. R., Fung, A., Mohammadi, F., \& Raahemifar, K. (2014). A Survey on Advanced Metering Infrastructure. Electrical Power and Energy Systems, 63, 473 - 484.

NIST (2010). NIST Framework and Roadmap for Smart Grid Interoperability Standards. Release 1.0, National Institute of Standards and Technology, Tech. rep. January.

Nomura, K., Kashiwagi, T., Yamashita, T., \& Kawade, T. (2014). Solution tom Utilisation of Smart Meter Data. FUJITSU Sci. Tech. J., 50(2): $58-66$.

Prasad, I. (2014). Smart Grid Technology: Application and Control. International Journal of Advanced Research in Electrical, Electronics and Instrumentation Engineering, 3(5): 9533 - 9542.

Puradbhat, S., \& Banerjee, R. (2014). Estimating Demand Side Management Impacts on Buildings in Smart Grid. Department of Energy Science and Engineering, IIT Bombay, Mumbai, India.

Quora (2016). What is Self-healing in Smart Grid? Quora. April. Https://www.Quora.com/what-is-self-healing-in smartgrid.

Qureshi, A. J., Gul, M., \& Qureshi, W. (2010). Demand Side Management through innovative load Control. Tencon, 580 585.

Rogers, F. D., \& Polak, G. G. (2013). Optimal Clustering of Time Periods for Electricity Demand Side Management. IEEE Transactions on power Systems, $1-10$.

Rumley, S., Kagi, E., Rudnick, H., \& Germond, A. (2008). Multi-Agent Approach to electrical Distribution Networks Control. Annual IEEE International Computer Software and Applications Conference.

Sagar, E. V., \& Prasad, P. V. N. (2013). Reliability Improvement of Radial Distribution System with Smart Grid Technology. Proceeding of the World Congress on Engineering and Computer Science, 23 - 25 October, I, San Francisco, USA.

Sakthivel, K., \& Winton, D. P. (2014). Application of Optimisation Techniques in Smart Grids. International Journal of Science, Engineering and Technology Research, 3(1): $32-36$.

Salani, M., Giusti, A., Di Caro, G., Rizzoli, A. E., \& Gambardella, L. M. (2011). Lexicographic multi-objective optimization for the unit commitment problem and economic dispatch in a microgrid, 2nd IEEE PES Innovative Smart Grid Technologies, $1-8$.

Samadi, P., Mohsenian-Rad, H., Schober, R., \& Wong, V. W. S. (2012). Advanced Demand Side Management for the Future Smart Grid using Mechanism Design. Work Support in Part by a Strategic Project Grant (STPGP-396838) from the Natural Science and Engineering Research Council of Canada (NSERC), (Accepted May 20, 2012).

SGA (2011). Smart Grid Apps: Six trends that will shape grid evolution. https://gigaom.com/report/smart-grid-apps-sixtrends-that-will-shape-grid-evolution/ (Accessed 10th of May, 2019)

SGS (2018). Smart Grid Security: Threats, Vulnerabilities and Solutions, Smart Grid Awareness. Https://smartgridawareness.org. (Accessed 26 $6^{\text {th }}$ of July, 2018).

Silva, N., Marsh, D., Rodrigues, A., \& Pinto, C. M. (2011). Dynamic SCADA/DMS Data Model-Plug \& Play Smart Grid Solutions. $21^{\text {st }}$ International Conference on Electricity Distribution, CIRED, 6 - 9, June, 1022, 1 - 4.

TRSG (2011). Technology Roadmap Smart Grids. International Energy Agency. http://www.iea.org/publications/ freepublications/publication/smartgrids roadmap.pdf.

Ullah, M. N., Javaid, N., Khan, I., Mahmood, A., \& Farooq, M. U. (2013). Residential Energy Consumption Controlling Techniques to Enable Autonomous Demand Side Management in Future Smart Grid Communications. COMSATS Institute of IT, Islamabad, Pakistan.

Zhang, J., Ye, T., \& Hamada, N. (2012). R \& D Strategy for Smart Grids and Smart Cities in China. Hitachi Review, 61(5): $200-205$. 